\title{
Selección mediante LASSO adaptado para determinar las variables importantes de los videos en las campañas de crowdfunding españolas
}

\author{
Néstor A. Bruno Pérez ${ }^{1}$, Sandra Morini Marrero ${ }^{2}$
}

\begin{abstract}
Using a video is must in a crowdfunding campaigns to reach the asked funds. Moreover, the video success depends on several attributes. This paper analyzes a sample of Spanish crowdfunding platforms in order to find out which are the most relevant attributes of the video content to achieve success using adaptive lasso in order to select those variables and their impact in the success.
\end{abstract}

Keywords: crowdfunding, collaborative economy, experiential marketing, adaptive lasso, logistic regression

\section{RESUMEN}

En las campañas de crowdfunding la utilización del video es prácticamente una condición sine qua non para poder llegar a obtener la financiación solicitada, el video a su vez depende de gran cantidad de factores distintos. En nuestro trabajo estudiamos cuales son los factores más relevantes a tener en cuenta para ser utilizados en el video de la campaña de crowdfunding, utilizamos varias campañas en plataformas de crowdfunding del Reino de España en las que efectuamos primero una selección de los atributos utilizando LASSO adaptado, que llevará a conseguir los factores fundamentales a utilizar en el video para poder triunfar en la campaña.

Palabras clave: crowdfunding, economía colaborativa, Marketing experiencial, LASSO adaptado, regresión logística

Received: 03 de Noviembre del 2020

Accepted: 20 de Abril de 2021

\section{Introducción}

El crowdfunding o financiación en masas o micro mecenazgo, es una financiación alternativa a la financiación tradicional, que permite un incremento en las posibilidades de obtener financiación externa o de vender nuestros productos o servicios. Además, para que una campaña de crowdfunding tenga éxito debe tener la capacidad atraer a los potenciales mecenas.

Para dar a conocer la campaña de crowdfunding y que se alcance el éxito en la misma, el video es prácticamente una condición sine qua non, así lo expresan autores como Wheat et al. (2013), Barnett (2014), Cumming et al., (2014), Mata Monforte (2014), Mollick (2014) y Koch y Siering (2015) indican que si se utiliza un video en la campaña de crowdfunding es más probable la obtención de la financiación deseada.

Así Barnett (2014) expresa que la utilización de un video en la campaña crowdfunding llega a duplicar las probabilidades de éxito en la misma, Mollick y Kuppuswamy (2014) opinan que una de las razones más significativas de que la campaña de crowdfunding fracase es un video pobre, Koch y Siering (2015) muestran que los videos aumentan la aceptación del proyecto, ya que el visitante después de su visualización suele sentirse más familiarizado con los contenidos del mismo. Además, según estos autores a través del video se obtiene la información de forma menos laboriosa que leyendo el texto que acompaña a la campaña.

En nuestro trabajo estudiamos como diferentes atributos del video de la campaña de crowdfunding influyen en la obtención de la financiación solicitada de la campaña, considerando como éxito de la misma la obtención del objetivo de financiación. Dichos factores los dividiremos en tres partes a) los relacionados con el marketing experiencial, b) los relacionados con la comunicación y c) los relacionados con los aspectos técnicos del video.

El objetivo principal es averiguar qué variables del video promocional de la campaña de influyen positivamente en obtener el éxito de la misma. Por otro lado, esos factores se representan mediante variables de tipo dicotómico con valor cero cuando dicho factor no se encuentra en el video estudiado y uno cuando si está en el mismo.

Nuestro trabajo se divide en 5 secciones, la primero versa sobre marketing experiencial, lenguaje y comunicación, la segunda sobre las variables a estudiar, la tercero trata de la metodología, la cuarta habla de los resultados y la quinto versa sobre las conclusiones.

\section{Marketing experiencial, lenguaje y comuni- cación}

Tal y como se acaba de exponer en la introducción anterior, existe certeza en que la utilización del video en la campaña de crowdfunding favorece el éxito. Nuestro interés se centra

${ }^{1}$ Universidad de La Laguna, España. E-mail:nbruno@ull.edu.es

${ }^{2}$ Universidad de La Laguna, España. E-mail:smorini@ull.edu.es

How to cite: Bruno, N., Morini, S. (2021). Selección mediante LASSO adaptado para determinar las variables importantes de los videos en las campañas de crowdfunding españolas. Revista de Análisis Económico y Financiero, Vol.4,N.2, 13-27. DOI: 10.15446/ing.investig.xxxx 
qué elementos y características del video promueven el éxito de la campaña.

Nosotros analizaremos los atributos que componen el video bajo el prisma del marketing experiencial, desde el punto de vista de la comunicación y de los aspectos técnicos del video.

Aunque no se denominara marketing experiencial ya en los años 80 se empiezan a dar importancia a las emociones como elemento fundamental en el proceso de compra (Walls et al., 2011). En concreto, Holbrook y Hirschman (1982) consideraron que el procesamiento de información clásico descuidaba importantes elementos del consumo que involucran fantasías, sentimientos y diversión. La visión experiencial de Holbrook y Hirschman (1982) pone el énfasis en el significado simbólico, los procesos subconscientes y la recuperación del resultado no verbal del consumo. Esta perspectiva del marketing considera a las personas como sujetos emocionales que esperan obtener una experiencias satisfactorias y agradables. Experiencias que se manifiestan como eventos que implican a cada individuo de manera personal (Pine y Gilmore, 1998).

Así, según Schmitt (2006) son las experiencias las que las motivan la decisión de compra y producen una conexión entre el cliente con la marca-empresa. En efecto, en muchos productos y servicios las ofertas son muy similares lo que no permite una diferenciación entre las mismas, por lo que se ha hecho necesaria la elaboración de experiencias para poder competir y que no se perciban como estandarizados nuestros productos y servicios (Brakus et al., 2008; Carù y Cova, 2009). En la actualidad los potenciales clientes asumen determinadas características y las ventajas del producto o servicio, por lo que es la experiencia la que permite una diferenciación (Pine y Gilmore, 1998).

De esta forma, Schmitt (1999) indica que las compañías se han alejado del marketing tradicional de "características y beneficios" para crear experiencias para sus clientes.

Schmitt (2000) enumera 5 clases de experiencias que son los cimientos del marketing experiencial, que serán utilizados para analizar los elementos del video:

a. Marketing de sensaciones, que se dirige crear experiencias sensoriales a través de los 5 sentidos. Se usa para obtener diferenciación, para motivar al cliente y para agregar valor al producto o servicio.

b. Marketing de sentimientos, va dirigido a las emociones de los clientes para poder elaborar experiencias que originen estados emocionales positivos a favor de la marca.

c. Marketing de pensamientos, se dirige a la parte intelectual con objeto de crear experiencias cognitivas que solucionen problemas y que cautiven a los clientes con métodos creativos, mediante la provocación, la intriga y la sorpresa.

d. Marketing de actuaciones, que va dirigido a aspectos como las vivencias corporales, interactuación entre las personas y estilos de vida. Enriquece la vida de los clientes mostrándoles nuevas experiencias físicas y maneras diferentes de realizar las cosas.

e. Marketing de relaciones, contiene algunos aspectos de los otros tipos de marketing experiencial y apela al afán de mejora del sujeto
En la línea de Bueno García (2000, pp. 131-132) indicar que el mensaje en la publicidad se codifica con una amalgama de lenguajes y por eso son "mensajes múltiples". La publicidad, a pesar de utilizar poco tiempo para informar, es rico en la utilización de muchos extranjerismos, palabras compuestas, préstamos, calcos y jerga; además se utilizan todo tipo de figuras retóricas y tiene una importante presencia de calificativos y de oraciones apelativas.

Por otra parte, muchos elementos de la comunicación están estrechamente relacionados con el marketing experiencial, pero abarcan más de un campo por lo que resulta difícil asociarlo a sensaciones, sentimientos, pensamientos, actuaciones o relaciones de forma exclusiva por lo que se debe tener en cuenta como aspecto de las comunicaciones.

Aunque como indica Galmés Cerezo (2015) si bien hoy en día podría hablarse de comunicación experiencial no todas las comunicaciones relacionadas con el marketing son en absoluto experienciales y también deben analizarse.

Las características técnicas del video, más allá de su contenido y su relación con los diferentes niveles del marketing experiencial y los elementos de la comunicación en si, también se han revelado como un aspecto de suma importancia para llegar a la obtención de la financiación solicitada en las campañas. Así, Iruzubieta et al. (2011) concluyen que la mayoría de los encuestados espera que el video tenga calidad y de no ser así se puede tener una percepción negativa de la marca.

\section{Variables a estudiar}

En el presente trabajo se utilizan 217 variables relacionadas con el video de la campaña, dichas variables se pueden observar en el anexo 1. Las hemos dividido en tres grupos:

a. Las relacionadas con el marketing experiencial.

b. Las relacionadas con la comunicación.

c. Relacionadas con las características técnicas del video.

a. A su vez el marketing de experiencial lo hemos subdividido en: i) sensaciones, ii) sentimientos, iii) pensamientos, iv) actuaciones y v) relaciones.

i. Dentro del marketing de sensaciones hemos estudiado 26 variables diferentes que se subdividen a su vez en:

- Relacionadas con la identidad de marca, con variables como que se explique el producto o servicio, su identidad visual o que planteé que exista una marca. De estas a priori la que se nos antoja a priori más importante es que se plantee la existencia de una marca (X7) dado que Steinberg y DeMariá (2012) expresan que uno de los motivos principales del fracaso en las campañas de crowdfunding es la falta de una visión de marca.

- Con la vista (el color) como que predominen los tonos vivos o apagados, que los haya contraste entre los colores. Los colores pueden tener efectos psicológicos en los consumidores, comunican información y diferentes significados culturales y sociales (Caivano y López, 2007; Elliot et al., 2007; Marshall 2010; Minah, 2008; Takahashi 2012). 
- En cuanto a las relacionadas con el oído (músicasonido) estudiamos factores como que hubiera música en el video, que la música fuera cantada, que fuera suave, que fuera grave que hubiera jingles, que existan periodos de silencio. Se debe tener en cuenta que La música es particularmente importante debido a su potencial para afectar y mejorar la excitación del espectador (Gorn, 1982; Park y Young, 1986; Stout y Leckenby, 1988; Berger y Mitchell, 1989). Por otra parte, Alpert et al. (2005) expresan que, si en el anuncio no se busca la racionalidad, una canción puede servir para dar notoriedad y conseguir ventas.

- El estilo con variables como que sea sencillos, o dinámicos o potentes. El estilo es la cualidad distintiva, constante y coherente de la expresión sensorial y está compuesto de los elementos primarios relacionados con los cinco sentidos (Schmitt, 2000).

ii. Con respecto al marketing de sentimientos, hemos utilizado 29 variables como que como se utilizan emociones primarias, secundarias, actitud entusiasta, relajante, estresante, melancólica. . .

Aaker y Stayman (1992) y Moral Moral y Fernández Alles (2012) expresan que la experiencia del cliente está relacionada sus emociones más íntimas del mismo, teniéndose como meta crear hacia la marca una experiencia afectiva que desarrolle un vínculo sentimental de alegría y de orgullo.

Russel (1980) y Pike y Ryan (2004) basándose en una secuencia emocional de motivación expresan como la actitud entusiasta no es adecuada como experiencia positiva que si puede ser la actitud relajante y estresante pero que la más adecuada es la actitud entusiasta.

iii. El marketing de pensamientos, utilizamos 22 variables

- La primera de ellas es la referente al tipo de pensamiento que De Bono (1989) define como pensamiento lateral, no se restringe a un único plano, sino que se mueve en planos múltiples y simultáneos y dado que Wittmann et al. (2008) concluyen que el contraste facilita las decisiones y que cuando se toman decisiones creativas se produce una liberación de dopamina por parte del cerebro que crea sensaciones placentera en el sujeto, por lo que parece razonable suponer que para conectar mejor con los aportantes es más adecuado utilizar el pensamiento divergente o lateral.

- Otras variables son las relacionadas con los sesgos cognitivos. Hay una enorme cantidad de sesgos, algunos con más de una denominación y otros muy parecidos entre ellos, hemos analizado un total de 20 sesgos entre ellos el efecto anclaje (Lichtenstein y Slovic, 1971; Tversky y Kahneman, 1973), El efecto aislamiento (Kahneman y Tversky, 1979 y 1982), efecto manada (Leibenstein, 1950), El efecto halo (Thorndike, 1920), ...

iv. Respecto al marketing de actuaciones, hemos estudiado 18 hipótesis
- La primera subdivisión es la de protagonistas del video: famosos, expertos, usuarios. Ogilvy (1985), Petty et al. (1983), Misra y Beatty (1990), Kalhe y Homer (1985) indican que hay controversia acerca del uso de celebridades en el marketing, por un lado, se concluye que usa a un famoso aumenta la posibilidad de que recuerde el anuncio, pero no hace cambiar la opinión. Por otro lado, los testimonios no deben ser genéricos sino específicos y lo más mesurables que sea posible, además se debe identificar claramente al que da el testimonio (De Montigny, 2017). De igual forma, Rodríguez del Pino et al. (2014, pp. 118-126) indican que la recomendación favorable sobre el producto que hacen, según convenga, famosos, especialistas en el asunto o consumidores, es fundamental.

- Otro grupo de variables son las relacionadas con la utopía y locus amoenius como por ejemplo que el nivel cultural sea alto, clase social alta, situación bucólica... Así Manca et al. (2012) explican que expresar situaciones utópicas y relacionarlas con el productos y servicio ayuda a asociar situaciones placenteras con la marca, es una manera también de sacar del mundo anodino en que se encuentran los clientes potenciales del que podrían sacarlo el producto o servicio. Manca y Manca (2012) opinan que esta situación también se puede conseguir con la utilización de paisajes que expresen libertad, tranquilidad o felicidad. Incluso se pueden utilizar otros momentos históricos o lugares de un hipotético futuro.

- Mientras que otro grupo es el relacionado con la experiencia corporal, así según Schmitt (2006) las experiencias corporales pueden estar basadas en el cuerpo, las acciones motoras, las señales corporales y las influencias ambientales sobre los deseos físicos.

v. Respecto al marketing de relaciones, hemos utilizado 34 hipótesis

- Relacionado con los estereotipos así Del Moral Pérez (2000) y Garrido Lora (2007) presuponemos que en una sociedad moderna los estereotipos no promueven el éxito de la campaña.

- Que se identifique con un grupo o un lugar geográfico, Mata Monforte (2014) y Fondevila Gascón et al. (2015) indican que es importante que se use una idea que conecte con un colectivo con el que el mecenas se sienta relacionado o por el que sienta empatía.

- Medios sociales digitales con un H1.5.3.a hasta H1.5.3.c en el video se plantea la conexión mediante alguna red social, de la plataforma, ... Jenkins y Deuze (2008), Kelly et al. (2010) y Colistra y Duvall (2017) indican que los patrocinadores quieren comunicarse con los creadores a lo largo de todo el proceso, desean una comunicación bidireccional y recibir actualizaciones de los creadores, como parte importante de su experiencia necesitan sentirse parte del proceso de creación de proyectos. 
b) Relacionadas con la comunicación los subdividimos en i) lenguaje y ii) semiótica

i. Respecto al lenguaje tenemos 47 variables, el apartado se subdivide a su vez en 3 partes:

- Idioma cómo que el idioma principal sea un idioma del estado español, el castellano, el catalán, que se pueden poner subtítulos... Hernando Cuadrado (1994) indica que al receptor de los anuncios le agrada que sea en su lengua autóctona, mientras que García Vilas (2015) expresa que el anuncio subtitulado en el propio idioma del anuncio trae ventajas pues estos en ocasiones se ven en entornos que tienen demasiado ruido o que están en silencio.

- Narrativa de con variables como el mensaje es sencillo, se narra el proyecto, se narra la historia del emprendedor, oraciones apelativas... Liu et al. (2014) indican que el receptor del video puede empatizar identificándose con el creador o con el usuario del producto/servicio, esto crea dos posibles estrategias en el ámbito de la narración para el video de crowdfunding: contar la historia desde la perspectiva del emprendedor o desde la perspectiva del posible financiador. Mientras que Agrawal et al. (2014) concluyen que trasmitir confianza y honradez es para que un mecenas decida financiar o no un proyecto. Los mecenas necesitan estar seguros de saber a dónde y a quien van los fondos. Así que el emprendedor además de contar el proyecto, debe explicar su trayectoria, su reputación y su personalidad.

- Figuras retóricas y tropos como se utilizan al menos tres tropos, se utilizan figuras de omisión, repetición, de comparación, de contradicción... Los estudios demuestran que los publicistas suelen recurrir a las figuras retóricas porque así garantizan su recuerdo (McQuarrie y David, 1992; Leigh, 1994; McQuarrie y Mick, 1996 y 1999). Aunque hay algunas que le resultan muy complejas para el receptor del anuncio como le sucede a la hipérbole (Callister et al., 2007) y el juego de palabras (Bueno García, 2000). Por otra parte, Everaert-Desnedt (1984), Hoeken (1995) y Gutiérrez Ordóñez (1997) hacen referencia al uso de la interrogación retórica en los anuncios con la finalidad de buscar en el receptor una respuesta afirmativa a la pregunta.

ii. En cuanto a la semiótica usamos 18 variables, como nivel icónico, iconográfico, tropológico, códigos gestuales, hay un mito... Eco (1986) indica una distinción entre niveles icónicos, iconográficos y tropológicos. Por otra parte, los gestos que se transforman en signos debido a la disposición del destinatario o del emisor, que traduce esa conducta a signos (Eco, 1977; Le Breton, 1994; Sánchez Corral, 2006; Farinango, 2017).

c) Respecto a las características técnicas del video estudiamos 23 variables como que el video es de calidad, duración del video, no se graba a contraluz, se hace un call to action, ... Mott (2012) indica que en el crowdfunding el video debe ser breve. Mord y Gilson (1985), Patzer (1991) y Steinberg y DeMaria (2012) son más estrictos en relación al tiempo y considera que es fundamental aprovechar los primeros 30 segundos; en concreto, el emprendedor debería ser capaz de presentar su propuesta de valor durante los primeros 10 segundos del video. Steinberg y DeMaria (2012) añaden que el video no tiene porqué ser profesional, pero sí mantener cierto grado de calidad, asegurándose que los segmentos no están entrecortados, mal iluminados o son difíciles de discernir, y que el audio sea claro y comprensible. Clair (2014) recomienda hacer el Call to action al final del video. Mientras que Renvoise y Morin (2007) indican que los comienzos y los finales son importantes, teniendo mucha importancia la primera impresión y también el final de un comunicado.

\section{Selección de atributos mediante regresión regularizada}

Cuando se realiza el análisis bajo una óptica de éxito-fracaso, el método más adecuada para establecer como contribuye cada variable, teniendo en cuenta las demás, bajo una perspectiva de éxito-fracaso es la regresión logit. Para la cual la variable respuesta es:

$$
Y_{i}=\left\{\begin{array}{l}
1, \quad \text { si la } i \text {-esima campaña es exitosa } \\
0, \quad \text { si la } i \text {-esima campaña es un fracaso }
\end{array}\right.
$$

Y la especificación genérica del modelo es:

$$
P\left(Y_{i}=1 / X_{i}\right)=\frac{e^{\beta X_{i}}}{1+e^{\beta X_{i}}}
$$

donde $X_{i}$ es el vector de las variables no dependientes de los videos analizados, en la campaña $i$-esima *

Ninguno de estos modelos se aplica directamente considerando todos los atributos que han sido propuestos. Hay que tener en cuenta que muchos de los atributos que se han introducido no se corresponden a investigaciones realizadas con respecto a las campañas de crowdfunding sino en el ámbito del marketing y la publicidad, y aunque parece lógico suponer que los factores que contribuyen al éxito de una campaña de marketing también contribuyan al éxito de una campaña de recaudación de fondos no tiene por qué ser así. En este caso, se dispone de una amplia batería de atributos y el objetivo del trabajo no es analizar la capacidad predictiva de ninguna de ellas en particular, por lo que creemos necesario realizar antes de estimar el modelo, la selección de los factores que se muestren verdaderamente con relevancia.

El proceso de selección-aprendizaje automático de variables trata de elegir el más adecuado grupo de variables que expliquen los datos de la forma más sencilla posible, con el propósito de no emplear grados de libertad en variables no necesarias que incorporen ruido en la estimación y produzcan multicolinealidad. Según Guyon y Elisseeff

*El vector $X_{i}$ no contiene exactamente todos los atributos analizados sino solo aquellos que se manifiestan como más importantes a la hora de explicar el éxito

${ }^{\dagger}$ Para profundizar en estos procedimientos se puede consultar: Millar (2002), Weisberg (2005) o Hastie et al. (2009) 
(2003) el objetivo de la selección de atributos es triple: mejorar el desempeño de la predicción en sí, proporcionar predictores más rápidos y efectivos en términos de coste y proporcionan una mejor comprensión del proceso subyacente que generan los datos.

De igual forma, Hastie et al. (2009) expresan que si se reducen las variables mejorará la precisión de las predicciones de los modelos de regresión lineal, reduciendo algunos coeficientes o estableciendo su valor en cero, es decir, sacrificando un poco de sesgo con el fin de reducir la varianza de los valores predichos; y por otro, facilita la interpretación del modelo; se obtiene una visión general del mismo sacrificando los pequeños detalles.

Además, Kursa y Rudnicki (2010) señalan que trabajar con conjuntos de atributos de gran tamaño tiene dos inconvenientes, uno menor y puramente técnico que se traduce en la necesidad de emplear más recursos para la estimación del modelo y su posible uso para predicción, y otro más importante que afecta directamente a la precisión de las estimaciones que empeoran si el número de variables es significativamente superior al óptimo.

Por otro lado, tomando la predicción como meta de selección de variables, que es el caso que nos ocupa cuando se toma como variable a explicar el éxito-fracaso de la campaña, Beyene et al. (2009) proponen usar como criterio el error de clasificación o el área bajo la curva AUROC (Area Under Receiver Operating Characteristic) y perseguir su minimización.

La regresión regularizada añade restricciones o penalizaciones a un modelo con la finalidad de evitar su sobreajuste $y$, por tanto, mejorar su generalización a otra muestra de datos. En la regularización, a la función de pérdida tradicional* se le añade un término que, generalmente en los modelos de regresión, es la norma L1 o L2 con una ponderación ajustable $\lambda$ que especifica el tamaño de la regularización.

\section{LASSO adaptado}

Este procedimiento es propuesto por Zou (2006) con el fin de contrarrestar el sesgo de las estimaciones obtenidas por LASSO, para ello se añaden pesos a los coeficientes. Estos pesos, w, pueden obtenerse de una estimación previa de los coeficientes $w_{j}=1 /\left|\beta_{j}\right|^{\gamma}$ (con $\gamma>0$ ) o por validación cruzada, pudiendo variar en función de $\lambda^{\S}$. De esta forma, aunque LASSO es un caso particular de regularización por red elástica, LASSO adaptado no lo es.

La principal ventaja de este procedimiento respecto a otros es que tiene propiedades "oráculo". En general, un estimador oráculo es consistente en la estimación de los parámetros y en la selección de las variables, es decir, no sólo identifica el subconjunto correcto de atributos, sino que además su estimación es óptima (Zou, 2006).

Para la regresión lineal, los coeficientes, $\beta$ se estiman minimizando:

$$
\widehat{\beta}=\arg \min _{\beta}\left\{\frac{1}{2 p}\|y-X \beta\|^{2}+\lambda|w \beta|\right\}
$$

donde $w=\sum_{j=1}^{p} w_{j}$ y $p$ el número de regresores.
Para la regresión logística, de forma similar, se sustituye la penalización de la regularización por red elástica por $\lambda|w \beta|$, resultando en:

$$
\widehat{\theta}=\arg \min _{\theta}\left\{\frac{-l\left(\theta_{0}-\theta\right)}{p}+\lambda|w \beta|\right\}
$$

\section{Resultados}

Nuestro trabajo abarca videos que van del 1 de septiembre de 2017 hasta el 30 de junio de 2019, se han analizado un total de 551 campañas de crowdfunding con video para campañas de crowdfunding de donación, recompensa y venta anticipada".

Además, durante ese periodo en esas plataformas cotejamos un total de 736 campañas de crowdfunding que no aportan video. Como primera aproximación a la importancia del video para obtener la financiación solicitada, se encuentra que el $18 \%$ (135 sobre 736 ) de las campañas sin video analizadas tienen éxito, frente al 53\% (293 sobre 551) de las campañas con video.

La base de datos elaborada en el estudio utiliza además de la plataforma, la clase de campaña, la cifra de mecenas, la cantidad que se consigue y la que se solicita y cuánto dura el video; estos factores posibilitaran mostrar la variable dependiente éxito-fracaso, y se utilizan como variables de control en el modelo estudiado. Además, utiliza las variables dicotómicas que precisamos y permiten realizar el contraste de las hipótesis explicadas en el capitulo 2.

Tanto la plataforma como el tipo de crowdfunding parecen estar relacionados con el éxito. Así como la cantidad de mecenas y los fondos obtenidos, pero esa correspondencia es lógica y no aporta información, habida cuenta además que no es controlable por el emprendedor que solicita los fondos. La cantidad que se solicita manifiesta algo de relación con el éxito de la campaña. Además, el tiempo que dura el video no es determinante.

\section{Análisis de la clasificación éxito/fracaso}

En esta parte del estudio seguimos la línea de las variables explicadas anteriormente en un ambiente de éxito-fracaso de la campaña. Al ser la variable dependiente de carácter dicotómico se muestra adecuada la utilización regresión logística. En lo que respecta a la presentación, en general, cuando se saben la lista de variables con relevancia para el estudio se contrastan dos modelos mediante la regresión logística, uno que incorpora las variables de control y otro que no. Con respecto a las variables de control, la plataforma de referencia es GoFundme y el de donación es el tipo de crowdfunding de referencia. Por otra parte, se incluye como variable de control el logaritmo de la cantidad solicitada; no se emplea ni el número de donantes ni la cantidad conseguida porque son variables sobre las que el solicitante

*Suma de los errores al cuadrado, $\sum(\hat{y}-y)^{2}$, para la regresión lineal $\sum-y * \log (\hat{y})-(1-y) * \log (1-\hat{y})$, en el caso de la regresión logística $(y$ es la variable dependiente e $\hat{y}$ su predicción)

${ }^{+} \mathrm{Si} \lambda=0$ se estaría ante un modelo no regularizado.

¥Se penalizan más los coeficientes con estimaciones iniciales bajas.

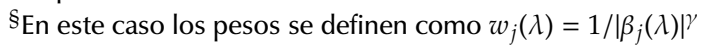

${ }^{\mathbb{I}}$ Las plataformas utilizadas son Gofundme, Goteo, Kickstarter, Lanzanos, PatrocinaM, Ulule y Verkami. 
de financiación no puede tomar decisiones y no se considera la duración del video porque en el análisis univariante se reveló que no tenía relación con el éxito/fracaso de la campaña.

\section{LASSO Adaptado}

El procedimiento LASSO adaptado sobre la submuestra de entrenamiento de las variables posibles obtiene una selección de 85 factores relevantes*, siendo los cinco con más importancia: actitud entusiasta (X42), utilizar un nivel tropológico (X173), evocar la cultura de un lugar geográfico (X101), usar Twitter como canal de comunicación (X119) y mostrar emociones secundarias positivas (X34)

Las variables utilizadas sobre la muestra de datos de entrenamiento y de testeo generan los resultados que se recogen en la Tabla 1; el tanto por ciento de aciertos y también el AUC bajo la curva ROC son algo menores en la muestra de testeo que en la de entrenamiento. Además, el porcentaje de aciertos es estadísticamente significativo para un p-valor $<2 e^{-16}$ tanto para entrenamiento como para testeo, y su valor es alto, superior al $87 \%$ para entrenamiento y algo por debajo del $79 \%$ para el testeo. Por otro lado, el error de tipo I es bajo, en torno al $6 \%$ en la muestra de entrenamiento y del $11.71 \%$ en la de testeo. En este caso, el procedimiento sobreestima la muestra de entrenamiento, por lo que posteriormente obtiene un rendimiento peor al registrado inicialmente en la muestra de testeo.

Tabla 1. Matrices de confusión y medidas de desempeño para muestreo de entrenamiento (izquierda) y de testeo (derecha) utilizando Lasso Adaptado y validación cruzada repetida $(10,10)$

\begin{tabular}{|c|c|c|c|c|c|c|}
\hline & & \multicolumn{3}{|c|}{ Entrenamiento Real } & \multicolumn{2}{|c|}{ Testeo Rea } \\
\hline & & Ex & $\mathrm{Fr}$ & & Ex & $\mathrm{Fr}$ \\
\hline \multirow[t]{3}{*}{ Predicho } & Ex & 203 & 26 & Ex & 48 & 13 \\
\hline & $\mathrm{Fr}$ & 31 & 180 & $F r$ & 11 & 39 \\
\hline & & \multicolumn{3}{|c|}{ Entrenamiento } & \multicolumn{2}{|c|}{ Testeo } \\
\hline AUROC & & \multicolumn{2}{|c|}{$87.06 \%$} & & \multicolumn{2}{|c|}{$78.18 \%$} \\
\hline Exactitud & & \multicolumn{2}{|c|}{$87.05 \%$} & & \multicolumn{2}{|c|}{$78.37 \%$} \\
\hline Error Tipo I & & \multicolumn{2}{|c|}{$5.90 \%$} & & \multicolumn{2}{|c|}{$11.71 \%$} \\
\hline Puntuación F & & \multicolumn{2}{|c|}{$87.69 \%$} & & \multicolumn{2}{|c|}{$80.00 \%$} \\
\hline
\end{tabular}

En la Tabla se expresan sólo las variables significativas al 99\% y $95 \%$ de confianza y el resto de resultados están en el anexo II. A destacar algunos, como que la probabilidad de éxito de la campaña con video en las plataformas Goteo, Ulule y Verkami es $99 \%$, 93\% y $89 \%$ superior que en la plataforma de referencia; por otra parte, el éxito de la campaña se muestra independiente del tipo de campaña, además, no hay evidencia estadísticamente significativa de que a mayor cantidad solicitada haya menor probabilidad de éxito.

Como factores seleccionados por su aportación al éxito debemos mencionar los siguientes factores: el usar el nivel tropológico en los videos (X173), actitud entusiasta (X42), que se utilice twitter (X119), que se empleen códigos gestuales (X176), que la música sea suave (X17), que expresa confianza u honradez (X35), que aparezca alguna emoción secundaria negativa (X39) y la mujer no está estereotipada (X97).

Las variables que no facilitan el éxito según la regresión logística son las siguientes: recalcar el uso de la interrogación retórica (X164), que se narre aspectos de la personalidad del emprendedor (X155), se utiliza interrogación retórica (X164), el efecto señuelo (X60), que se plantee una situación bucólica (X91), se utilizan códigos linguísticos no habituales (X136) y emplear música grave (X19).

Se observan diferencias en término de valor de los coeficientes y significación individual de algunos atributos entre el modelo con y sin variables de control. Posiblemente se deben a que parte del impacto del atributo sobre el éxito de la campaña es recogido por el efecto de estas variables de control.

Con respecto al desempeño conjunto del modelo, el error típico con variables de control es de 247.94 y sin variables de control de 326.92, siendo estos valores muy inferiores a la desviación del modelo nulo, que como ya indicamos, alcanza 761.62. El AIC es, respectivamente, 433.94 y 494.92. Con respecto a la matriz de confusión (Tabla $3)$, los dos modelos tienen un tanto por ciento de acierto estadísticamente significativo ( $p$-valor $<2 e^{-16}$ ), siendo las medidas de desempeño del modelo con variables de control algo mejores. Además, son de buena calidad los valores del área bajo la curva ROC (89.67 y $83.90 \%$ ) y alcanzan también altos valores en la exactitud, mientras que el error de tipo I muestra valores muy adecuados en ambos casos.

Por tanto, aunque inicialmente, parecía que el procedimiento se adecuaba demasiado a la muestra de entrenamiento en detrimento de la generalización, posteriormente se revela que las variables elegidas de forma conjunta logran un buen desempeño en términos de error.

Matrices de confusión y medidas de desempeño para muestreo de entrenamiento (izquierda) y de testeo (derecha) utilizando Lasso Adaptado y validación cruzada repetida $(10,10)$.

\section{Conclusiones}

La existencia del video en la campaña favorece el éxito de la misma como indican Wheat et al. (2013), Barnett (2014), Cumming et al. (2014), Mata Monforte (2014), Mollick (2014) y Koch y Siering (2015), aspecto que también resulta evidente en nuestro estudio, puesto que observamos que de 736 campañas de crowdfunding que no tenían video sólo 135 consiguieron la financiación perseguida, es decir el 18\%, frente al 53\% de éxito (293 sobre 551) de las campañas que estudiamos que sí tenían video. Wheat et al. (2013) añaden que el video es generalmente la parte más importante del atractivo del crowdfunding.

La dificultad principal a la hora de establecer estas conclusiones es elegir qué atributos consideramos finalmente relevantes, una revisión de los resultados expuestos en el capítulo cuarto pone de manifiesto que hay tres factores que más influyen en la contribución al éxito si la selección es por LASSO adaptado como son el el usar el nivel

*Por orden de importancia, los atributos seleccionados son: $X 42, X 173$, $X 101, X 119, X 34, X 39, X 114, X 105, X 176, X 97, X 45, X 189, X 195$, $X 160, X 132, X 3, X 122, X 35, X 17, X 133, X 159 \_b, X 41, X 127, X 66$, $X 106, X 96, X 81, X 113, X 177, X 181, X 46, X 191, X 183, X 130, X 166$, $X 16, X 190, X 64, X 179, X 199, X 182, X 128, X 107, X 58, X 108, X 146$, $X 14, X 56, X 90, X 141, X 7, X 178, X 194, X 145, X 103, X 38, X 193$, $X 160 \_c, X 187, X 23, X 51, X 60, X 22, X 10, X 71, X 25, X 44, X 125$, $X 204, X 91, X 174, X 161, X 138, X 26, X 54, X 33, X 70, X 164, X 79$, $X 95, X 100, X 19, X 155, X 136$ y X123. De estos atributos aquellas variables con probabilidad cero el logit los elimina de la tabla resultado; por lo que no aparecen en el anexo ni X182 ni X194 
Tabla 2. Regresión logic con las variables seleccionadas mediante Lasso Adaptado

\begin{tabular}{|c|c|c|c|c|c|c|c|c|c|c|}
\hline & Estimac. & odd-ratio & Probab. & p-valor & & Estimac. & odd-ratio & Probab. & p-valor & \\
\hline Intercepto & -3.824 & & & 0.1165 & & $-6.90 \mathrm{E}+00$ & & & 0 & $* * *$ \\
\hline Goteo & 4.188 & 65.88 & $99 \%$ & 0 & $* * *$ & & & & & \\
\hline Ulule & 2.548 & 12.78 & $93 \%$ & 0.0087 & $* * *$ & & & & & \\
\hline Verkami & 2.124 & 8.37 & $89 \%$ & 0.0159 & $* *$ & & & & & \\
\hline X17 & 1.638 & 5.14 & $84 \%$ & 0.002 & $* * *$ & 0.842 & 2.32 & $70 \%$ & 0.0394 & $* *$ \\
\hline X19 & -1.449 & 0.23 & $19 \%$ & 0.0018 & $* * *$ & -0.767 & 0.46 & $32 \%$ & 0.0379 & $* *$ \\
\hline X35 & 1.877 & 6.53 & $87 \%$ & 0.0355 & $* *$ & 1.388 & 4.01 & $80 \%$ & 0.0416 & $* *$ \\
\hline X39 & 1.591 & 4.91 & $83 \%$ & 0.0063 & $* * *$ & 1.512 & 4.54 & $82 \%$ & 0.0015 & $* * *$ \\
\hline X42 & 2.844 & 17.18 & $95 \%$ & 0 & $* * *$ & 2.611 & 13.61 & $93 \%$ & 0 & $* * *$ \\
\hline X60 & -2.129 & 0.12 & $11 \%$ & 0.0181 & $* *$ & -1.722 & 0.18 & $15 \%$ & 0.0157 & $* *$ \\
\hline X91 & -1.404 & 0.25 & $20 \%$ & 0.025 & $* *$ & -0.979 & 0.38 & $27 \%$ & 0.0413 & $* *$ \\
\hline X97 & 1.606 & 4.98 & $83 \%$ & 0.0196 & $* *$ & 1.204 & 3.33 & $77 \%$ & 0.0247 & $* *$ \\
\hline X100 & -1.347 & 0.26 & $21 \%$ & 0.0081 & $* * *$ & -1.14 & 0.32 & $24 \%$ & 0.0042 & $* * *$ \\
\hline X101 & 1.168 & 3.21 & $76 \%$ & 0.0122 & $* *$ & 0.97 & 2.64 & $73 \%$ & 0.0082 & $* * *$ \\
\hline X105 & 1.675 & 5.34 & $84 \%$ & 0.0176 & $* *$ & 1.442 & 4.23 & $81 \%$ & 0.0143 & $* *$ \\
\hline X108 & 1.346 & 3.84 & $79 \%$ & 0.1736 & & 1.513 & 4.54 & $82 \%$ & 0.0354 & $* *$ \\
\hline X119 & 3.768 & 43.31 & $98 \%$ & 0.0217 & $* *$ & 4.666 & 106.27 & $99 \%$ & 0.0038 & $* * *$ \\
\hline X122 & 4.462 & 86.67 & $99 \%$ & 0.0774 & & 4.046 & 57.17 & $98 \%$ & 0.0184 & $* *$ \\
\hline X136 & -2.076 & 0.13 & $11 \%$ & 0.0001 & $* * *$ & -1.818 & 0.16 & $14 \%$ & 0 & $* * *$ \\
\hline X155 & -2.564 & 0.08 & $7 \%$ & 0.0002 & $* * *$ & -1.704 & 0.18 & $15 \%$ & 0.0011 & $* * *$ \\
\hline X160 & 1.204 & 3.33 & $77 \%$ & 0.0401 & $* *$ & 0.98 & 2.66 & $73 \%$ & 0.023 & $* *$ \\
\hline X164 & -2.833 & 0.06 & $6 \%$ & 0.0029 & $* * *$ & -2.22 & 0.11 & $10 \%$ & 0.0033 & $* * *$ \\
\hline X173 & 3.439 & 31.15 & $97 \%$ & 0 & $* * *$ & 2.574 & 13.12 & $93 \%$ & 0 & $* * *$ \\
\hline X176 & 1.381 & 3.98 & $80 \%$ & 0.0099 & $* * *$ & 1.03 & 2.8 & $74 \%$ & 0.0137 & $* *$ \\
\hline X189 & 0.734 & 2.08 & $68 \%$ & 0.1619 & & 0.866 & 2.38 & $70 \%$ & 0.039 & $* *$ \\
\hline
\end{tabular}

Tabla 3. Matrices de confusión y medidas de desempeño de modelos de regresión logística para el global de la muestra estimados con variables seleccionadas por Lasso Adaptado.

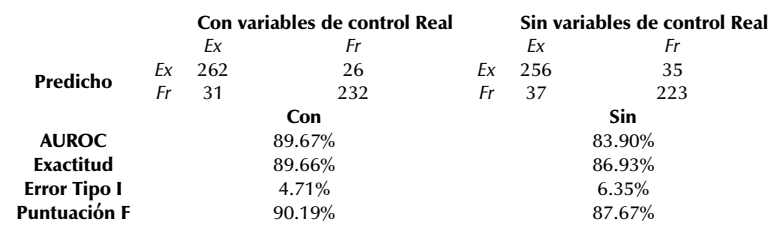

tropológico en los videos (X173), actitud entusiasta (X42), el uso de twitter como medio de conexión (X119) pero también a tener en cuenta influyen positivamente atributos como que se empleen códigos gestuales (X176), que la música sea suave (X17), que expresa confianza u honradez (X35), que aparezca alguna emoción secundaria negativa (X39) y la mujer no está estereotipada (X97).

En cuanto a los factores negativos para la obtención de la financiación en campaña destacar el uso de preguntas retóricas (X164), narrar acerca de la personalidad del emprendedor (X155), que se usen códigos linguísticos no usuales (X136), el efecto señuelo (X60), en menor medida, pero también estadísticamente significativa, emplear música grave (X19).

La utilización de los aspectos tropológicos en los videos (X173), se incluyó en nuestro estudio siguiendo el trabajo de Eco (1986, pp. 233-236) que explica que el nivel tropológico es el equivalente audiovisual a los tropos verbales y que se usa bastante en la publicidad. Efectivamente, los resultados que hemos obtenido parecen indicar que este nivel es importante para incrementar las posibilidades de éxito. El atributo actitud entusiasta (X42) se incluyó en nuestro estudio debido a que Russell (1980) y Pike y Ryan (2004) indicaban que una actitud entusiasta es la más adecuada para que los clientes tengan una experiencia que recuerden, aspecto que se puede extender también a los anuncios, dado que los anuncios con una actitud entusiasta tienen más posibilidades de que sean vistos por los potenciales clientes como una experiencia positiva a tener en cuenta. En definitiva, los resultados parecen sugerir que mostrar una actitud entusiasta no solo favorece que los receptores del mensaje tengan una experiencia positiva y que recuerden, sino que contribuye a que, en el caso de las campañas de crowdfunding, estén más dispuestos a aportar fondos a esta, por tanto, se corrobora lo indicado por Steinberg y DeMaria (2012, pp. 33-34) que señalan la importancia de una actitud positiva y entusiasta y además expresa lo importante de ser natural lo que nos llevó a incluir el atributo expresa confianza u honradez (X35).

Por otra parte, el uso de redes sociales está en consonancia con lo expresado por CECARM (2014), Barrio Carrasco (2017, pp. 74-97) que sugieren que esto sucede con cualquier medio digital, mientras que Martínez Álvarez (2014) lo especifica en referencia a Twitter.

En relación al lenguaje corporal, éste es sumamente importante y es una parte esencial para lograr ser un comunicador eficiente, Peace (2012) y Ferrari (2017, pp. 5-45) indican la importancia de los códigos gestuales adecuados a la hora de transmitir (códigos gestuales, X176). Además, Park y Young (1986) concluyen que el efecto de la música en la actitud sobre la marca depende del tipo de intervención y de su nivel. La música facilita la actitud sobre la marca si la implicación del espectador es baja, pero es un efecto distractor si el espectador está implicado 
cognitivamente. lo cual va en consonancia con que la utilización de música suave (X17) se muestre positiva y que la música grave (X19) dificulte el éxito de la campaña de crowdfunding.

El factor que aparezca alguna emoción secundaria negativa (X39) lo incluimos suponiendo que las emociones se utilizan en la publicidad para causar una réplica afectiva, donde las emociones provocadas por la publicidad se transportan a la marca (Zeitling y Westwood, 1986; Aaker y Stayman, 1992; Gutiérrez, 2002) pero a fe de ser sinceros pensábamos que iba a mostrarse como un factor negativo, creemos que en nuestro caso se muestra como factor a utilizar debido a la importancia que tiene en el crowdfunding la capacidad de hacer sentir lastima para facilitar los donativos.

La mujer no está estereotipada (X97) con un resultado positivo va en la línea de expresado por Del Moral Pérez (2000) concluye que, como parte de una sociedad más igualitaria, los estereotipos van perdiendo su intensidad.

El uso de la interrogación retorica como aspecto negativo a evitar no está del todo en con sonancia con los trabajos Everaert-Desnedt (1984), Hoeken (1995) y Gutiérrez: mientras que se narren aspectos en los que salga aspectos de la personalidad del emprendedor (X155) como atributo que no favorece el éxito no va en consonancia de lo indicado por Mott (2012), Tarcomnicu (2017) y Acconcia (2017), con respecto a utilizar códigos linguísticos no habituales (X136) como factor no favorecedor del éxito no va en la línea de lo comentado por Ferraz Martínez (2005, p. 31) mientras que el efecto señuelo (X60) como factor inadecuado no va en consonancia con lo que a priori hubiéramos pensado (Joule et al., 1989).

Para finalizar, se debe matizar que estas conclusiones dependen de haber planteado como factor de éxito de la campaña el alcanzar el objetivo de financiación; consideramos adecuado otro estudio en el que sea el grado de consecución la variable dependiente a analizar.

\section{Referencias}

Aaker, D. A. y Stayman, D. M. (1992) Implementing the Concept of Transformational Advertising, Psychology \& Marketing, 9 (3), pp. 237-253.

Agrawal, S. (2014). Neuromarketing in Action: How to Talk and Sell to the Brain, Journal of Consumer Marketing, 31(5), pp. 404-405. doi:ttp://dx.doi.org/10.1108/JCM-02-20140879 .

Barnett, C. (2014). Better Than A Google Search: Crowdfunding Q\&A with Kay Koplovitz and Chance Barnett, video, duracion 51:45. https://youtu.be/22DkpQc4o5s, consultado 9 de julio de 2020.

Beier, M. y Wagner, K. (2015). Crowdfunding Success: A Perspective from Social Media and E-Commerce, Thirty Sixth International Conference on Information Systems, Fort Worth, Texas.

Beyene, J., Atenafu, E.G., Hamid, J.S., To, T., y Sung, L. (2009). Determining relative importance of variables in developing and validating predictive models. BMC Medical Research Methodology, 9 (1), pp. 64-73.

Bueno Garcia, A. (2000). Publicidad y Traduccion, Monograficos de la Revista Hermeneus, $\mathrm{n}^{\underline{0}}$ 2, Excma. Diputacion
Provincial de Soria, Soria. Callister, M. A., Lesa A. y Stem, L. A. (2007). The Role of Visual Hyperbole in Advertising Effectiveness, Journal of Current Issues and Research in Advertising, 29 (2), pp. 1-14.

CECARM (2014). Tu Plan de Marketing en Redes Sociales Implantacion y Estrategias, Proyecto CECARM, https://www.cecarm.com/tu-plan-de-marketing-enredes-sociales-implantacion-y-estrategias.pdf-6121. Consultado el 18 de junio de 2018.

Barrio Carrasco, J. (2017). La influencia de los medios sociales digitales en el consumo. La funcion prescriptiva de los medios sociales en la decision de compra de bebidas refrescantes en España, Tesis Doctoral, Facultad de Ciencias de la Informacion, Universidad Complutense de Madrid.

Colistra, R. y Duvall, K. (2017). Show Me the Money: Importance of Crowdfunding Factors on Backers' Decisions to Financially Support Kickstarter Campaigns, Social Media + Society, octubre-diciembre, pp. 1-17. doi.org/10.1177/2056305117736942.

Cumming, D. J., Leboeuf, G. y Schwienbacher, A. (2014). Crowdfunding Models: Keep-it-All vs. All-or-Nothing, Working Paper, SKEMA Business School, Lille, Francia.

De Bono E. (1989). El Pensamiento Lateral; Manual de Creatividad, Paidos Plural, Barcelona.

Delgado Ballester, E. y Fernandez Sabiote, M. E. (2011). Marcas de Experiencia: Marcando la Diferencia, Estudios Gerenciales, 27 (121), pp. 59-77.

De Montigny, B. (2017). Testimonial Marketing: Pros and Cons, working paper, AAD 617, University of Oregon.

Del Moral Perez, M. E. (2000). Los Nuevos Modelos de Mujer y de Hombre a traves de la Publicidad, Comunicar, 14, pp. 208-217.

Eco, U. (1986). La Estructura Ausente; Introduccion a la Semiotica, Editorial Lumen, Barcelona.

Elliot, A. J., Markus A. Maier, M. A., Moller, A. C. y Friedman. R. (2007). Color and Psychological Functioning: The Effect of Red on Performance Attainment, Journal of Experimental Psychology: General, 136 (1), pp. $154\{168$. doi:10.1037/00963445.136.1.154.

Everaert-Desnedt, N. (1984). La Communication Publicitaire: Etude Semiopragmatique, Cabay, Louvain-La-Neuve.

Ferraz Martınez, A. (1995). El Lenguaje de la Publicidad, Arco Libros, Madrid.

Garcia Vilas, S. (2015). La Publicidad Subtitulada, Marketing News, 14-abril-

Hernando Cuadrado, L. A. (1994). Semiotica y modernidad, Semiotica y modernidad, en Jose M. Paz Gago, Jose Angel Fernandez Roca, Carlos J. Gomez Blanco (eds.), Actas del V Congreso internacional de la Asociacion Española de Semiotica, A Coruña, 1992, Coruña: Universidade. Servizo de publicacions, vol. II, pp. 513-523.

Holbrook, M. B. y Hirschman, E. C. (1982). The experiential aspects of consumption: Consumer fantasies, feelings, and fun, Journal of Consumer Research, 9, pp. $132\{140$.

Kahneman, D. y Tversky, A., (1979). Prospect Theory: An Analysis of Decision under Risk, Econometrica, 47, (2), marzo, pp. 263-291. 
Koch, J. A. y Siering, M. (2015). Crowdfunding Success Factors: The Characteristics of Successfully Funded Projects on Crowdfunding Platforms, Proceedings of the 23rd European Conference on Information Systems (ECIS 2015); abril, Muenster, Alemania.

Le Breton, D. (1994). Lo imaginario del cuerpo en la tecnociencia, Reis: Revista española de investigaciones sociologicas, 68, pp. 197-210. 2017.

Lichtenstein, S. y Slovic, P. (1971). Reversals of Preference between Bids and Choices in Gambling Decisions. Journal of Experimental Psychology, 89(1), pp. 46-55.

Manca, L., Manca, A. y Pieper, G. W. (2012). Introduction Probing Madison Avenue's, en Manca, L., Manca, A. y Pieper, G. W. (eds), Utopian Images and Narratives, pp. 1-6, Lexingtom Books, Lanham, Maryland.

Martınez Alvarez, S. A. (2014). El Uso de Twitter como Plataforma de Atencion al Cliente en las Organizaciones, Cuadernos de Gestion de Informacion, 4, pp. 27-37

Martın Nuñez, M. (2014). El Pitching 2.0: Conceptualizacion y Cesarrollo en Proyectos de Crowdfunding, Historia y Comunicacion Social, 19, pp. 821-832.

Mata Monforte, J. (2014). Las Campañas de Crowdfunding, su Eficacia en Proyectos Lucrativos y Causas Sociales, Facultat de Cuminacio i Relacions Internacionals Blanquema, Universitat Ramon Llull, Tesis Doctoral, julio, Barcelona.

McQuarrie, E. F. y David G. M. (1992). On Resonance: A Critical Pluralistic Inquiry into Advertising Rhetoric, Journal of Consumer Research, 19, pp. $180\{197$

Mollick, E. (2014), The dynamics of crowdfunding: An exploratory study, Journal of Business Venturing, 29, pp. 1\{16. doi.org/10.1016/j.jbusvent.2013.06.005

Park, C. W. y Young S. M. (1986). Consumer Response to Television Commercials: The Impact of Involvement and Background Music on Brand Attitude Formation, Journal of Marketing Research, 23, pp. 11-24.

Petty, R., Cacioppo, J. y Schumann D. (1983). Central and peripheral routes to advertising effectiveness: the moderating role of involvement, Journal of Consumer Research, 10, pp. $135\{46$

Pike, S. y Ryan, C. (2004). Destination Positioning Analysis through a Comparison of Cognitive, Affective, and Conative Perceptions, Journal of Travel Research, 42, pp. 333-342. doi: 10.1177/0047287504263029

Schmitt, B. H. (2006). Experiential Marketing, DEUSTO, Barcelona.

Steinberg, S. M. y DeMaria, R., (2012). The Crowdfunding Bible: How to Raise Money for Any Startup, Video Game or Proyect, Kimmmich, J. (ed).

Wheat, R. E., Wang, Y., Byrnes, J. E. y Ranganathan J. (2013). Raising money for scientific research through crowdfunding, Trends in Ecology \& Evolution, 28 (2), pp. 71-72. doi.org/10.1016/j.tree.2012.11.001

Wittmann, B. C., Daw, N. D., Seymour, B. y Dolan, R. J. (2008). Striatal Sctivity Underlies Novelty-based Choice in Humans, Neuron, 58 (6), pp. 967-973. doi:10.1016/j.neuron.2008.04.027
Zou, H. (2006). The adaptive lasso and its oracle properties, Journal of the American Statistical Association, 101 (476), pp. 1418-1429. doi: 10.1198/016214506000000735. 


\section{Anexo 1}

Hipótesis Propuestas y Variables Utilizadas en el Análisis

\begin{tabular}{|c|c|c|}
\hline Hipótesis & Variable & Marketing Experiencial \\
\hline & & MARKETING DE SENSACIONES \\
\hline & & Identidad de marca \\
\hline H1.1.1.a & $\mathrm{x} 1$ & Se muestra algún tipo de identidad visual del producto o servicio en el video \\
\hline H1.1.1.b & $\times 2$ & Se explica el producto o servicio. \\
\hline H1.1.1.C & X 3 & Se plantea la existencia de una marca. \\
\hline H1.1.1.d & $\mathrm{X} 4$ & Se muestra la marca como diferente. \\
\hline H1.1.1.e & $X 5$ & Se muestra la marca como algo tangible. \\
\hline H1.1.1.f & X 6 & La idea de negocio se explica de forma clara y concisa. \\
\hline H1.1.1.g & $\times 7$ & $\begin{array}{l}\text { Se explican los beneficios de patrocinar la campaña. } \\
\text { La vista (el color) }\end{array}$ \\
\hline H1.1.2.a & X 8 & El video es en color. \\
\hline $\mathrm{H} 1.1 .2 . \mathrm{b}$ & $\times 9$ & Predominan los colores vivos. \\
\hline H1.1.2.C & $\mathrm{X} 10$ & Predominan los colores apagados. \\
\hline $\mathrm{H} 1.1 .2 . \mathrm{d}$ & $\mathrm{X} 11$ & $\begin{array}{l}\text { Hay contraste de colores } \\
\text { El ofdo (música-sonido) }\end{array}$ \\
\hline H1.1.3.a & $\mathrm{X} 12$ & Tiene música. \\
\hline H1.1.3.b & X 13 & Tiene sólo música, no se habla. \\
\hline H1.1.3.C & X 14 & La música tiene que ver con la campaña, producto o servicio. \\
\hline H1.1.3.d & X 15 & Se utiliza música cantada. \\
\hline H1.1.3.e & $\mathrm{X} 16$ & Se canta en español. \\
\hline H1.1.3.f & $\mathrm{X} 17$ & La música es suave. \\
\hline H1.1.3.g & $\mathrm{X} 18$ & El volumen de la música es bajo. \\
\hline $\mathrm{H} 1.1 .3 . \mathrm{h}$ & $\times 19$ & La música es grave \\
\hline H1.1.3.i & $X 20$ & Hay periodos de total silencio. \\
\hline H1.1.3.j & $X 21$ & Hay un jingle o una tonadilla. \\
\hline H1.1.3.k & $X 22$ & $\begin{array}{l}\text { Todo el video es en silencio. } \\
\text { El estilo }\end{array}$ \\
\hline H1.1.4.a & X 23 & Sencillo. \\
\hline $\mathrm{H} 1.1 .4 . \mathrm{b}$ & $X 24$ & Realismo. \\
\hline H1.1.4.C & $\times 25$ & Dinámico. \\
\hline H1.1.4.d & $X 26$ & $\begin{array}{l}\text { Alto/Fuerte. } \\
\text { MARKETING DE SENTIMIENTOS/EMOCIONES }\end{array}$ \\
\hline H1.2.a & $X 27$ & Video informativo. \\
\hline H1.2.a & X 28 & Video emocional. \\
\hline H1.2.b & $\times 29$ & Emociones como un fin. \\
\hline H1.2.b & X 30 & Emociones como un medio. \\
\hline H1.2.C & X 31 & Emociones positivas. \\
\hline H1.2.d & X 32 & Emociones primarias positivas. \\
\hline H1.2.e & X 33 & Emociones primarias negativas. \\
\hline H1.2.f & X 34 & Emociones secundarias positivas. \\
\hline H1.2.f_1 & X 35 & Expresa confianza u honradez. \\
\hline H1.2.f_2 & X 36 & Expresa vitalidad. \\
\hline H1.2.f_3 & X 37 & Expresa ilusión u optimismo. \\
\hline $\mathrm{H} 1.2 . \mathrm{f}_{-} 4$ & X 38 & Expresa agradecimiento. \\
\hline H1.2.g & X 39 & Emociones secundarias negativas. \\
\hline H1.2.g_1 & $\mathrm{X} 40$ & Expresa lástima o pena o injusticia o remordimiento. \\
\hline H1.2.g_2 & $\mathrm{X} 41$ & Expresa indignación. \\
\hline $\mathrm{H} 1.2 . \overline{\mathrm{h}}$ & $\mathrm{X} 42$ & Actitud entusiasta. \\
\hline $\mathrm{H} 1.2 . \mathrm{i}$ & $\mathrm{X} 43$ & Actitud estresante. \\
\hline $\mathrm{H} 1.2 . \mathrm{j}$ & X 44 & Actitud melancólica. \\
\hline H1.2.k & X 45 & Actitud relajante. \\
\hline H1.2.I & $X 46$ & El emprendedor parece natural. \\
\hline H1.2.m & $\mathrm{X} 47$ & El emprendedor destaca lo positivo. \\
\hline H1.2.n & $\mathrm{X} 48$ & El emprendedor parece sincero. \\
\hline H1.2.o & X 49 & Intenta manipular claramente. \\
\hline H1.2.p & X 50 & Parece improvisado. \\
\hline $\mathrm{H} 1.2 . \mathrm{q}$ & X 51 & Parece aprendido de memoria. \\
\hline H1.2.r & X 52 & Intenta ser entretenido. \\
\hline
\end{tabular}




\begin{tabular}{|c|c|c|}
\hline H1.2.s & $\mathrm{X} 53$ & Se hace una actuación. \\
\hline $\mathrm{H} 1.2 . \mathrm{t}$ & X 54 & Intenta ser emocionante. \\
\hline \multirow[t]{2}{*}{$\mathrm{H} 1.2 . \mathrm{u}$} & X 55 & Se utiliza el humor. \\
\hline & & $\begin{array}{l}\text { MARKETING DE PENSAMIENTOS } \\
\text { Pensamientos }\end{array}$ \\
\hline $\mathrm{H} 1.3 .1$ & X 56 & $\begin{array}{l}\text { Usa pensamiento divergente. } \\
\text { Sesgos cognitivos }\end{array}$ \\
\hline $\mathrm{H} 1.3 .2$ & X 57 & Utiliza algún sesgo cognitivo \\
\hline $\mathrm{H} 1.3 .2 \_1$ & X 58 & Efecto anclaje. \\
\hline $\mathrm{H} 1.3 .2 \_2$ & X 59 & Sesgo de confirmación. \\
\hline $\mathrm{H} 1.3 .2 \_3$ & X 60 & Efecto señuelo. \\
\hline $\mathrm{H} 1.3 .2_{-}^{-} 4$ & X 61 & El efecto aislamiento. \\
\hline $\mathrm{H} 1.3 .2 \_5$ & X 62 & El descuento hiperbólico. \\
\hline $\mathrm{H} 1.3 .2 \_6$ & X 63 & Efecto denominación. \\
\hline $\mathrm{H} 1.3 .2-7$ & X 64 & Efecto encuadre o Framing effect. \\
\hline $\mathrm{H} 1.3 .2 \_8$ & X 65 & El efecto dotación. \\
\hline $\mathrm{H} 1.3 .2 \_9$ & X 66 & Distorsión de las probabilidades. \\
\hline $\mathrm{H} 1.3 .2 \_10$ & X 67 & Aspecto cierto. \\
\hline $\mathrm{H} 1.3 .2-11$ & X 68 & Exceso de optimismo. \\
\hline $\mathrm{H} 1.3 .2^{-} 12$ & $\times 69$ & Efecto manada. \\
\hline $\mathrm{H} 1.3 .2-13$ & $\times 70$ & Preferencia por lo domestico. \\
\hline $\mathrm{H} 1.3 .2 \_14$ & X 71 & Sesgo del status quo. \\
\hline $\mathrm{H} 1.3 .2 \_15$ & $X 72$ & Sesgo del conservadurismo. \\
\hline $\mathrm{H} 1.3 .2 \_16$ & X 73 & Sesgo de la frecuencia de base. \\
\hline $\mathrm{H} 1.3 .2^{-}-17$ & X 74 & Sesgo de representatividad. \\
\hline $\mathrm{H} 1.3 .2^{-} 18$ & X 75 & La ley de los pequeños números. \\
\hline $\mathrm{H} 1.3 .2 \_19$ & $X 76$ & Efecto de Von Restorff. \\
\hline $\mathrm{H} 1.3 .2 \_20$ & X 77 & El efecto halo. \\
\hline & & MARKETING DE ACTUACIONES \\
\hline H1.4.1.a & $X 78$ & $\begin{array}{l}\text { Protagonistas del video: famosos, expertos, usuarios, emprendedor } \\
\text { El producto o servicio lo recomienda un famoso, un usuario, un experto o un } \\
\text { personaje de ficción. }\end{array}$ \\
\hline H1.4.1.a_1 & X 79 & Lo recomienda un famoso. \\
\hline H1.4.1.a_2 & $X 80$ & Se usan testimonios de usuarios. \\
\hline H1.4.1.a_3 & $X 81$ & Lo recomienda un experto. \\
\hline H1.4.1.a_4 & X 82 & Lo recomienda un personaje de ficción. \\
\hline H1.4.1. $\bar{b}$ & X 83 & Salen colaboradores. \\
\hline H1.4.1.C & X 84 & El video lo presenta el emprendedor o alguien muy vinculado al proyecto. \\
\hline H1.4.1.d & X 85 & El foco del video está en el emprendedor. \\
\hline H1.4.1.e & X 86 & El foco del video está en el potencial financiador. \\
\hline H1.4.1.f & X 87 & $\begin{array}{l}\text { Salen varias personas (más de cinco). } \\
\text { La utopía y locus amoenius }\end{array}$ \\
\hline H1.4.2.a & X 88 & Se plantea una clase social o situación utópica. \\
\hline H1.4.2.b & X 89 & Se plantea una clase alta. \\
\hline H1.4.2.C & X 90 & Se plantea un nivel cultural alto. \\
\hline $\mathrm{H} 1.4 .2 . \mathrm{d}$ & X 91 & Se plantea una situación bucólica. \\
\hline H1.4.2.e & $\times 92$ & Se plantea una situación en la naturaleza o el exterior \\
\hline $\mathrm{H} 1.4 .2 . \mathrm{f}$ & X 93 & Se plantea una fiesta o situación festiva. \\
\hline & & Experiencia corporal \\
\hline H1.4.3.a & X 94 & Se muestran experiencias corporales positivas. \\
\hline $\mathrm{H} 1.4 .3 . \mathrm{b}$ & X 95 & Se realizan pausas en la experiencia positiva. \\
\hline & & MARKETING DE RELACIONES \\
\hline & & Estereotipos \\
\hline H1.5.1.a & X 96 & Aparecen personajes no estereotipados. \\
\hline H1.5.1.a_1 & X 97 & La mujer no está estereotipada \\
\hline H1.5.1.a- 2 & X 98 & El hombre no está estereotipado \\
\hline H1.5.1. $\bar{b}$ & X 99 & Aparecen niños. \\
\hline & & Identificación con un grupo o lugar geográfico \\
\hline H1.5.2.a & $\times 100$ & Se evoca la cultura de algún grupo. \\
\hline H1.5.2.b & X 101 & Se evoca la cultura de un lugar geográfico \\
\hline H1.5.2.C & X 102 & Se evoca la cultura de un grupo de edad. \\
\hline H1.5.2.d & X 103 & Se evoca la cultura de una época. \\
\hline
\end{tabular}




\begin{tabular}{|c|c|c|}
\hline H1.5.2.e & $\mathrm{X} 104$ & Se evoca la cultura de un grupo deportivo. \\
\hline H1.5.2.f & X 105 & Se evoca la cultura de una marca. \\
\hline $\mathrm{H} 1.5 .2 . \mathrm{g}$ & X 106 & Se evoca una identidad social. \\
\hline H1.5.2.h & X 107 & $\begin{array}{l}\text { Se intenta que el aportante se sienta parte de un grupo por } \\
\text { consumir el producto o servicio. }\end{array}$ \\
\hline H1.5.2.i & $X 108$ & Se muestran relaciones familiares. \\
\hline H1.5.2.j & X 109 & Se muestran papeles sociales. \\
\hline H1.5.2.k & X 110 & Se muestra una vestimenta emblemática. \\
\hline H1.5.2.I & X 111 & Se realiza claramente algún tipo de segmentación. \\
\hline H1.5.2.I_1 & X 112 & Utiliza segmentación demográfica. \\
\hline H1.5.2.I_2 & X 113 & Utiliza segmentación socioeconómica. \\
\hline H1.5.2.I_3 & $X 114$ & Utiliza segmentación psicográfica. \\
\hline H1.5.2.I_4 & X 115 & Utiliza segmentación conductual. \\
\hline $\mathrm{H} 1.5 .2 . \mathrm{m}$ & X 116 & $\begin{array}{l}\text { Se intenta conectar con un colectivo. } \\
\text { Medios Sociales Digitales }\end{array}$ \\
\hline H1.5.3.a & X 117 & $\begin{array}{l}\text { En el video se plantea la conexión con los potenciales o futuros } \\
\text { financiadores o clientes a través de un medio digital. }\end{array}$ \\
\hline H1.5.3.a_1 & X 118 & Whatsapp. \\
\hline H1.5.3.a_2 & X 119 & Twitter. \\
\hline H1.5.3.a_3 & $X 120$ & Facebook. \\
\hline H1.5.3.a_4 & X 121 & Instagram. \\
\hline H1.5.3.a_5 & X 122 & Linkedin. \\
\hline H1.5.3.a_6 & $X 123$ & YouTube. \\
\hline H1.5.3.a_7 & X 124 & Blog. \\
\hline H1.5.3.a_8 & $X 125$ & Web. \\
\hline H1.5.3.a_9 & $X 126$ & E-mail. \\
\hline H1.5.3.a_10 & $X 127$ & Plataforma de crowdfunding. \\
\hline $\mathrm{H} 1.5 .3 . \mathrm{b}$ & $X 128$ & Justo debajo del video se accede a alguna red social \\
\hline H1.5.3.C & X 129 & $\begin{array}{l}\text { Se solicita redifusión } \\
\text { Comunicación } \\
\text { LENGUAJE } \\
\text { Idioma }\end{array}$ \\
\hline H2.1.1.a & X 130 & El idioma principal es cualquier lengua del Estado Español. \\
\hline H2.1.1.a_1 & X 131 & El idioma principal es español o castellano. \\
\hline H2.1.1.a_2 & X 132 & El idioma principal es catalán. \\
\hline H2.1.1.a_3 & X 133 & El idioma principal es vasco. \\
\hline H2.1.1.a_4 & X 134 & El idioma principal es gallego. \\
\hline $\mathrm{H} 2.1 .1 . \mathrm{b}$ & X 135 & El video tiene o permite poner subtítulos \\
\hline $\mathrm{H} 2.1 .1 . \mathrm{C}$ & X 136 & Se utilizan códigos linguísticos no habituales. \\
\hline H2.1.1.d & X 137 & $\begin{array}{l}\text { Se utiliza lenguaje sencillo. } \\
\text { Narrativa }\end{array}$ \\
\hline H2.1.2.a & X 138 & En el video se habla en exceso. \\
\hline $\mathrm{H} 2.1 .2 . \mathrm{b}$ & X 139 & Se utilizan sustantivos valorativos. \\
\hline $\mathrm{H} 2.1 .2 . \mathrm{C}$ & $X 140$ & El mensaje es sencillo. \\
\hline $\mathrm{H} 2.1 .2 . \mathrm{d}$ & X 141 & El argumento es original. \\
\hline H2.1.2.e & X 142 & Se reitera el mensaje. \\
\hline $\mathrm{H} 2.1 .2 . \mathrm{f}$ & X 143 & Se utilizan frases nominales. \\
\hline $\mathrm{H} 2.1 .2 . \mathrm{g}$ & X 144 & Se utiliza infinitivo. \\
\hline $\mathrm{H} 2.1 .2 . \mathrm{h}$ & X 145 & Se utilizan adjetivos. \\
\hline $\mathrm{H} 2.1 .2 . \mathrm{i}$ & X 146 & Se utilizan oraciones apelativas. \\
\hline H2.1.2.j & X 147 & Se utilizan oraciones interrogativas, exclamativas o imperativas \\
\hline $\mathrm{H} 2.1 .2 . \mathrm{j} \_1$ & X 148 & Se utilizan oraciones interrogativas. \\
\hline $\mathrm{H} 2.1 .2 . \mathrm{j} \_2$ & X 149 & Se utilizan oraciones exclamativas. \\
\hline H2.1.2.j_3 & X 150 & Se utilizan oraciones imperativas. \\
\hline $\mathrm{H} 2.1 .2 . \mathrm{k}$ & X 151 & Se narra la historia sobre el origen del proyecto/idea \\
\hline H2.1.2.I & X 152 & $\begin{array}{l}\text { Se narra la historia personal del emprendedor, su reputación o experiencia } \\
\text { previa y/o su personalidad }\end{array}$ \\
\hline H2.1.2.I_1 & X 153 & Se narra la historia personal del emprendedor \\
\hline H2.1.2.I_2 & X 154 & Se narra la reputación o experiencia previa del emprendedor. \\
\hline H2.1.2.I_3 & X 155 & $\begin{array}{l}\text { Se narra acerca de la personalidad del emprendedor. } \\
\text { Figuras Retóricas y tropos }\end{array}$ \\
\hline $\mathrm{H} 2.1 .3 . \mathrm{a}$ & $X 156$ & Utiliza tropos o figuras retóricas (al menos tres tipos). \\
\hline $\mathrm{H} 2.1 .3 . \mathrm{b}$ & X 157 & Se utilizan figuras de omisión. \\
\hline
\end{tabular}




\begin{tabular}{|c|c|c|}
\hline \multirow[t]{5}{*}{$\mathrm{H} 2.1 .3 . \mathrm{C}$} & $\mathrm{X} 158$ & Se utilizan figuras de repetición. \\
\hline & X 158a & $\begin{array}{l}\text { Aliteración, anadiplosis, anáfora, concatenación, epanadiplosis, geminación, } \\
\text { similicadencia }\end{array}$ \\
\hline & $\times 158 \mathrm{~b}$ & Paralelismo \\
\hline & $\mathrm{X} 158 \mathrm{c}$ & Polisíndeton \\
\hline & X 158d & Paranomasia \\
\hline \multirow[t]{4}{*}{$\mathrm{H} 2.1 .3 . \mathrm{d}$} & X 159 & Se utilizan figuras de comparación. \\
\hline & X 159a & Símil \\
\hline & X 159b & Metáfora \\
\hline & X 159c & Metonímia \\
\hline \multirow[t]{5}{*}{$\mathrm{H} 2.1 .3 . \mathrm{e}$} & X 160 & Se utilizan figuras de contradicción. \\
\hline & X 160a & Ironía \\
\hline & X 160b & Antítesis \\
\hline & X 160c & Oxímoron \\
\hline & X 160d & Paradoja \\
\hline H2.1.3.f & X 161 & Se utiliza hipérbole. \\
\hline $\mathrm{H} 2.1 .3 . \mathrm{g}$ & X 162 & Se utiliza enumeración. \\
\hline $\mathrm{H} 2.1 .3 . \mathrm{h}$ & X 163 & Se utiliza juego de palabras. \\
\hline H2.1.3.i & X 164 & $\begin{array}{l}\text { Se utiliza interrogación retórica. } \\
\text { SEMIÓTICA }\end{array}$ \\
\hline $\mathrm{H} 2.2 . \mathrm{a}$ & X 165 & Está presente la función emotiva o expresiva. \\
\hline $\mathrm{H} 2.2 . \mathrm{b}$ & X 166 & Está presente la función referencial o informativa \\
\hline $\mathrm{H} 2.2 . \mathrm{C}$ & X 167 & Está presente la función poética \\
\hline $\mathrm{H} 2.2 . \mathrm{d}$ & X 168 & Está presente la función fática \\
\hline $\mathrm{H} 2.2 . \mathrm{e}$ & X 169 & Se utilizan códigos no linguísticos. \\
\hline $\mathrm{H} 2.2 . \mathrm{f}$ & $\times 170$ & Se emplean códigos visuales \\
\hline $\mathrm{H} 2.2 . \mathrm{f} 1$ & X 171 & Se utiliza un nivel icónico. \\
\hline $\mathrm{H} 2.2 . \mathrm{f}_{-} 2$ & X 172 & Se utiliza un nivel iconográfico. \\
\hline $\mathrm{H} 2.2 . \mathrm{f}_{-} 3$ & X 173 & Se utiliza un nivel tropológico. \\
\hline $\mathrm{H} 2.2 . \bar{f} 4$ & X 174 & Se utiliza un nivel tópico. \\
\hline H2.2.f_5 & X 175 & Se utiliza un nivel entiménico. \\
\hline $\mathrm{H} 2.2 . \overline{\mathrm{g}}$ & X 176 & Se emplean códigos gestuales. \\
\hline H2.2.g_1 & X 177 & Se emplea el contacto visual. \\
\hline H2.2.g_2 & X 178 & Sonrie. \\
\hline $\mathrm{H} 2.2 . \overline{\mathrm{h}}$ & X 179 & Se emplean códigos acústicos. \\
\hline $\mathrm{H} 2.2 . \mathrm{i}$ & X 180 & Se utiliza algún mito. \\
\hline $\mathrm{H} 2.2 . \mathrm{j}$ & X 181 & Se muestran fotografías y/o gráficos. \\
\hline $\mathrm{H} 2.2 . \mathrm{k}$ & X 182 & $\begin{array}{l}\text { El video mantiene un orden. } \\
\text { Características técnicas del video }\end{array}$ \\
\hline H3.a & X 183 & El video es de calidad. \\
\hline H3.b & X 184 & Buena calidad de imagen. \\
\hline H3.c & X 185 & Buena calidad de audio. \\
\hline H3.d & X 186 & El video es muy breve (30 segundos o menos). \\
\hline H3.e & X 187 & El video dura tres minutos o menos. \\
\hline H3.f & X 188 & Se presenta la propuesta de valor al principio del video. \\
\hline H3.g & X 189 & Se graba en trípode \\
\hline H3.h & X 190 & Se graba de manera horizontal. \\
\hline $\mathrm{H} 3 . \mathrm{i}$ & X 191 & Se graba entre uno y dos metros. \\
\hline H3.j & X 192 & No se graba a contraluz. \\
\hline $\mathrm{H} 3 . \mathrm{k}$ & X 193 & Se graba en un ambiente tranquilo. \\
\hline H3.I & X 194 & Se utiliza un tono normal. \\
\hline H3.m & X 195 & Utiliza cortes. \\
\hline H3.n & X 196 & El lugar está iluminado. \\
\hline H3.o & X 197 & Se hace un call to action. \\
\hline H3.o_1 & X 198 & Se hace un call to action para pedir financiación. \\
\hline $\mathrm{H} 3 . \mathrm{O}_{-} 2$ & X 199 & Se hace un call to action para pedir difusión. \\
\hline H3.o_3 & $\times 200$ & Se hace un call to action para pedir colaboración. \\
\hline H3.o_4 & X 201 & Se hace un call to action al final del video. \\
\hline H3. $\bar{p}$ & X 202 & Se intenta obtener en algún momento un pico experiencial. \\
\hline H3.p_1 & X 203 & Pico experiencial al principio del video. \\
\hline H3.p_2 & X 204 & Pico experiencial al final del video. \\
\hline $\mathrm{H} 3 . \overline{\mathrm{q}}$ & X 205 & Se utiliza más de un video \\
\hline
\end{tabular}




\section{Anexo 2}

Lasso Adaptado para Éxito/Fracaso

\begin{tabular}{|c|c|c|c|c|c|c|c|c|c|c|}
\hline & Estimación & odd-ratio & Prob & p-valor & & Estimación & odd-ratio & Prob & p-valor & \\
\hline Intercepto & -3.824 & & & 0.1165 & & -6.9 & & & 0 & $* * *$ \\
\hline Goteo & 4.188 & 65.88 & $99 \%$ & 0 & $* * *$ & & & & & \\
\hline Kickstarter & -0.116 & 0.89 & $47 \%$ & 0.9194 & & & & & & \\
\hline Lanzanos & -0.269 & 0.76 & $43 \%$ & 0.7517 & & & & & & \\
\hline PatrocinaM & -1.371 & 0.25 & $20 \%$ & 0.2638 & & & & & & \\
\hline Ulule & 2.548 & 12.78 & $93 \%$ & 0.0087 & $* * *$ & & & & & \\
\hline Verkami & 2.124 & 8.37 & $89 \%$ & 0.0159 & $* *$ & & & & & \\
\hline Recompensa & 0.878 & 2.41 & $71 \%$ & 0.2133 & & & & & & \\
\hline Venta_ant & -0.064 & 0.94 & $48 \%$ & 0.9499 & & & & & & \\
\hline In(solic.) & -0.331 & 0.72 & $42 \%$ & 0.0749 & & & & & & \\
\hline $\mathrm{X} 3$ & 0.484 & 1.62 & $62 \%$ & 0.3378 & & 0.745 & 2.11 & $68 \%$ & 0.0788 & \\
\hline $\mathrm{X} 7$ & 0.223 & 1.25 & $56 \%$ & 0.7068 & & 0.064 & 1.07 & $52 \%$ & 0.8835 & \\
\hline $\mathrm{X} 10$ & -0.763 & 0.47 & $32 \%$ & 0.0871 & & -0.411 & 0.66 & $40 \%$ & 0.2464 & \\
\hline X14 & -0.267 & 0.77 & $43 \%$ & 0.5978 & & 0.193 & 1.21 & $55 \%$ & 0.6442 & \\
\hline $\mathrm{X} 16$ & 0.699 & 2.01 & $67 \%$ & 0.4405 & & 0.336 & 1.4 & $58 \%$ & 0.6164 & \\
\hline $\mathrm{X} 17$ & 1.638 & 5.14 & $84 \%$ & 0.002 & $* * *$ & 0.842 & 2.32 & $70 \%$ & 0.0394 & $* *$ \\
\hline X19 & -1.449 & 0.23 & $19 \%$ & 0.0018 & $* * *$ & -0.767 & 0.46 & $32 \%$ & 0.0379 & $* *$ \\
\hline $\mathrm{X} 22$ & -0.052 & 0.95 & $49 \%$ & 0.9782 & & -1.383 & 0.25 & $20 \%$ & 0.4305 & \\
\hline $\mathrm{X} 23$ & 0.39 & 1.48 & $60 \%$ & 0.5253 & & 0.347 & 1.41 & $59 \%$ & 0.4707 & \\
\hline X25 & -0.691 & 0.5 & $33 \%$ & 0.142 & & -0.546 & 0.58 & $37 \%$ & 0.1533 & \\
\hline $\mathrm{X} 26$ & 0.34 & 1.4 & $58 \%$ & 0.4955 & & 0.066 & 1.07 & $52 \%$ & 0.8743 & \\
\hline X33 & -0.927 & 0.4 & $28 \%$ & 0.1735 & & -0.832 & 0.44 & $30 \%$ & 0.1082 & \\
\hline X34 & 0.458 & 1.58 & $61 \%$ & 0.3803 & & 0.363 & 1.44 & $59 \%$ & 0.3767 & \\
\hline X35 & 1.877 & 6.53 & $87 \%$ & 0.0355 & $* *$ & 1.388 & 4.01 & $80 \%$ & 0.0416 & $* *$ \\
\hline X38 & -0.247 & 0.78 & $44 \%$ & 0.7753 & & -0.035 & 0.97 & $49 \%$ & 0.9602 & \\
\hline X39 & 1.591 & 4.91 & $83 \%$ & 0.0063 & $* * *$ & 1.512 & 4.54 & $82 \%$ & 0.0015 & $* * *$ \\
\hline $\mathrm{X} 41$ & 0.379 & 1.46 & $59 \%$ & 0.6894 & & 0.146 & 1.16 & $54 \%$ & 0.8354 & \\
\hline X42 & 2.844 & 17.18 & $95 \%$ & 0 & $* * *$ & 2.611 & 13.61 & $93 \%$ & 0 & $* * *$ \\
\hline $\mathrm{X} 44$ & -0.986 & 0.37 & $27 \%$ & 0.1779 & & -0.771 & 0.46 & $32 \%$ & 0.1705 & \\
\hline X45 & 0.58 & 1.79 & $64 \%$ & 0.4038 & & 0.8 & 2.22 & $69 \%$ & 0.1433 & \\
\hline X46 & 0.413 & 1.51 & $60 \%$ & 0.4147 & & 0.406 & 1.5 & $60 \%$ & 0.3263 & \\
\hline X51 & -0.927 & 0.4 & $28 \%$ & 0.0638 & & -0.404 & 0.67 & $40 \%$ & 0.3022 & \\
\hline X54 & -0.57 & 0.57 & $36 \%$ & 0.265 & & -0.532 & 0.59 & $37 \%$ & 0.204 & \\
\hline X56 & 0.378 & 1.46 & $59 \%$ & 0.3954 & & 0.251 & 1.28 & $56 \%$ & 0.5001 & \\
\hline X58 & 0.658 & 1.93 & $66 \%$ & 0.2964 & & 0.093 & 1.1 & $52 \%$ & 0.8479 & \\
\hline$X 60$ & -2.129 & 0.12 & $11 \%$ & 0.0181 & $* *$ & -1.722 & 0.18 & $15 \%$ & 0.0157 & $* *$ \\
\hline$X 64$ & 0.126 & 1.13 & $53 \%$ & 0.9116 & & 0.782 & 2.18 & $69 \%$ & 0.4375 & \\
\hline X66 & 5.651 & 284.71 & $100 \%$ & 0.2104 & & 3.828 & 45.97 & $98 \%$ & 0.0849 & \\
\hline X70 & -1.577 & 0.21 & $17 \%$ & 0.3805 & & -0.958 & 0.38 & $28 \%$ & 0.5595 & \\
\hline X71 & -2.588 & 0.08 & $7 \%$ & 0.5034 & & -4.789 & 0.01 & $1 \%$ & 0.0582 & \\
\hline X79 & -0.481 & 0.62 & $38 \%$ & 0.5036 & & -0.584 & 0.56 & $36 \%$ & 0.3315 & \\
\hline X81 & 0.723 & 2.06 & $67 \%$ & 0.1478 & & 0.282 & 1.33 & $57 \%$ & 0.4674 & \\
\hline X90 & 0.332 & 1.39 & $58 \%$ & 0.6433 & & 0.192 & 1.21 & $55 \%$ & 0.7138 & \\
\hline X91 & -1.404 & 0.25 & $20 \%$ & 0.025 & $* *$ & -0.979 & 0.38 & $27 \%$ & 0.0413 & $* *$ \\
\hline X95 & -3.58 & 0.03 & $3 \%$ & 0.1219 & & -2.802 & 0.06 & $6 \%$ & 0.1982 & \\
\hline X96 & -0.135 & 0.87 & $47 \%$ & 0.89 & & 0.283 & 1.33 & $57 \%$ & 0.6995 & \\
\hline X97 & 1.606 & 4.98 & $83 \%$ & 0.0196 & $* *$ & 1.204 & 3.33 & $77 \%$ & 0.0247 & $* *$ \\
\hline X100 & -1.347 & 0.26 & $21 \%$ & 0.0081 & $* * *$ & -1.14 & 0.32 & $24 \%$ & 0.0042 & $* * *$ \\
\hline X101 & 1.168 & 3.21 & $76 \%$ & 0.0122 & $* *$ & 0.97 & 2.64 & $73 \%$ & 0.0082 & $* * *$ \\
\hline X103 & 0.435 & 1.54 & $61 \%$ & 0.5119 & & 0.887 & 2.43 & $71 \%$ & 0.1041 & \\
\hline X105 & 1.675 & 5.34 & $84 \%$ & 0.0176 & $* *$ & 1.442 & 4.23 & $81 \%$ & 0.0143 & $* *$ \\
\hline X106 & 0.124 & 1.13 & $53 \%$ & 0.8483 & & 0.456 & 1.58 & $61 \%$ & 0.3461 & \\
\hline X107 & -1.258 & 0.28 & $22 \%$ & 0.1833 & & -0.648 & 0.52 & $34 \%$ & 0.4192 & \\
\hline X108 & 1.346 & 3.84 & $79 \%$ & 0.1736 & & 1.513 & 4.54 & $82 \%$ & 0.0354 & $* *$ \\
\hline X113 & 3.495 & 32.96 & $97 \%$ & 0.3393 & & 3.353 & 28.59 & $97 \%$ & 0.1453 & \\
\hline X114 & 0.823 & 2.28 & $69 \%$ & 0.1454 & & 0.669 & 1.95 & $66 \%$ & 0.1186 & \\
\hline X119 & 3.768 & 43.31 & $98 \%$ & 0.0217 & $* *$ & 4.666 & 106.27 & $99 \%$ & 0.0038 & $* * *$ \\
\hline X122 & 4.462 & 86.67 & $99 \%$ & 0.0774 & & 4.046 & 57.17 & $98 \%$ & 0.0184 & $* *$ \\
\hline
\end{tabular}




\begin{tabular}{|c|c|c|c|c|c|c|c|c|c|c|}
\hline & Estimación & odd-ratio & Prob & p-valor & & Estimación & odd-ratio & Prob & p-valor & \\
\hline $\mathrm{X} 123$ & -25.697 & 0 & $0 \%$ & 0.987 & & -25.39 & 0 & $0 \%$ & 0.9864 & \\
\hline X125 & -0.325 & 0.72 & $42 \%$ & 0.5573 & & -0.425 & 0.65 & $40 \%$ & 0.3404 & \\
\hline X127 & 0.276 & 1.32 & $57 \%$ & 0.6995 & & 0.583 & 1.79 & $64 \%$ & 0.3113 & \\
\hline X128 & -0.428 & 0.65 & $39 \%$ & 0.6516 & & 0.551 & 1.74 & $63 \%$ & 0.2328 & \\
\hline X130 & -0.472 & 0.62 & $38 \%$ & 0.3834 & & 0.086 & 1.09 & $52 \%$ & 0.8326 & \\
\hline X132 & 0.322 & 1.38 & $58 \%$ & 0.7031 & & 1.315 & 3.72 & $79 \%$ & 0.0546 & \\
\hline X133 & 18.164 & $7.00 \mathrm{E}+07$ & $100 \%$ & 0.9887 & & 18.53 & $1.10 \mathrm{E}+08$ & $100 \%$ & 0.9886 & \\
\hline X136 & -2.076 & 0.13 & $11 \%$ & 0.0001 & $* * *$ & -1.818 & 0.16 & $14 \%$ & 0 & $* * *$ \\
\hline X138 & -0.782 & 0.46 & $31 \%$ & 0.1586 & & -0.569 & 0.57 & $36 \%$ & 0.1825 & \\
\hline X141 & -0.185 & 0.83 & $45 \%$ & 0.7202 & & -0.242 & 0.79 & $44 \%$ & 0.5472 & \\
\hline X145 & 0.744 & 2.1 & $68 \%$ & 0.2633 & & -0.029 & 0.97 & $49 \%$ & 0.955 & \\
\hline X146 & 1.04 & 2.83 & $74 \%$ & 0.1795 & & 0.939 & 2.56 & $72 \%$ & 0.114 & \\
\hline X155 & -2.564 & 0.08 & $7 \%$ & 0.0002 & $* * *$ & -1.704 & 0.18 & $15 \%$ & 0.0011 & $* * *$ \\
\hline X159_b & 0.46 & 1.58 & $61 \%$ & 0.3451 & & 0.571 & 1.77 & $64 \%$ & 0.1379 & \\
\hline $\mathrm{X} 160$ & 1.204 & 3.33 & $77 \%$ & 0.0401 & $* *$ & 0.98 & 2.66 & $73 \%$ & 0.023 & $* *$ \\
\hline X160_C & 0.93 & 2.54 & $72 \%$ & 0.3162 & & -0.005 & 0.99 & $50 \%$ & 0.9944 & \\
\hline X161 & -0.056 & 0.95 & $49 \%$ & 0.9439 & & -0.642 & 0.53 & $34 \%$ & 0.3553 & \\
\hline X164 & -2.833 & 0.06 & $6 \%$ & 0.0029 & $* * *$ & -2.22 & 0.11 & $10 \%$ & 0.0033 & $* * *$ \\
\hline X166 & 0.104 & 1.11 & $53 \%$ & 0.8389 & & 0.486 & 1.63 & $62 \%$ & 0.2474 & \\
\hline X173 & 3.439 & 31.15 & $97 \%$ & 0 & $* * *$ & 2.574 & 13.12 & $93 \%$ & 0 & $* * *$ \\
\hline X174 & -1.31 & 0.27 & $21 \%$ & 0.7384 & & -0.728 & 0.48 & $33 \%$ & 0.6733 & \\
\hline X176 & 1.381 & 3.98 & $80 \%$ & 0.0099 & $* * *$ & 1.03 & 2.8 & $74 \%$ & 0.0137 & $* *$ \\
\hline X177 & 0.751 & 2.12 & $68 \%$ & 0.1238 & & 0.699 & 2.01 & $67 \%$ & 0.0749 & \\
\hline X178 & 0.472 & 1.6 & $62 \%$ & 0.3345 & & 0.279 & 1.32 & $57 \%$ & 0.4959 & \\
\hline X179 & 0.434 & 1.54 & $61 \%$ & 0.3513 & & 0.536 & 1.71 & $63 \%$ & 0.1304 & \\
\hline X181 & 0.247 & 1.28 & $56 \%$ & 0.6008 & & 0.314 & 1.37 & $58 \%$ & 0.4045 & \\
\hline X183 & -0.066 & 0.94 & $48 \%$ & 0.8943 & & 0.477 & 1.61 & $62 \%$ & 0.2193 & \\
\hline X187 & -0.054 & 0.95 & $49 \%$ & 0.9113 & & 0.117 & 1.12 & $53 \%$ & 0.7583 & \\
\hline X189 & 0.734 & 2.08 & $68 \%$ & 0.1619 & & 0.866 & 2.38 & $70 \%$ & 0.039 & $* *$ \\
\hline X190 & 0.474 & 1.61 & $62 \%$ & 0.3319 & & 0.367 & 1.44 & $59 \%$ & 0.3476 & \\
\hline X191 & 0.095 & 1.1 & $52 \%$ & 0.8275 & & -0.029 & 0.97 & $49 \%$ & 0.9375 & \\
\hline X193 & 0.8 & 2.23 & $69 \%$ & 0.1291 & & 0.495 & 1.64 & $62 \%$ & 0.2326 & \\
\hline X195 & 0.359 & 1.43 & $59 \%$ & 0.4932 & & 0.641 & 1.9 & $65 \%$ & 0.1265 & \\
\hline X199 & -0.133 & 0.88 & $47 \%$ & 0.8872 & & -0.149 & 0.86 & $46 \%$ & 0.8532 & \\
\hline X204 & 0.523 & 1.69 & $63 \%$ & 0.4074 & & 0.301 & 1.35 & $57 \%$ & 0.5545 & \\
\hline
\end{tabular}

